\section{Arrows in Biology: Lack of Clarity and Consistency Points to Confusion for Learners}

\section{Kate Wright, Jordan J. Cardenas, Phyllis Liang, and Dina L. Newman*}

Thomas H. Gosnell School of Life Sciences, Rochester Institute of Technology,

Rochester, NY 14623

\begin{abstract}
In this article, we begin to unpack the phenomenon of representational competence by exploring how arrow symbols are used in introductory biology textbook figures. Out of 1214 figures in an introductory biology textbook, 632 (52\%) of them contained arrows that were used to represent many different concepts or processes. Analysis of these figures revealed little correlation between arrow style and meaning. A more focused study of $\mathbf{8 6}$ figures containing 230 arrows from a second textbook showed the same pattern of inconsistency. Interviews with undergraduates confirmed that arrows in selected textbook figures were confusing and did not readily convey the information intended by the authors. We also present findings from an online survey in which subjects were asked to infer meaning of different styles of arrows in the absence of context. Few arrow styles had intrinsic meaning to participants, and illustrators did not always use those arrows for the meanings expected by students. Thus, certain styles of arrows triggered confusion and/or incorrect conceptual ideas. We argue that 1) illustrators need to be more clear and consistent when using arrow symbols, 2) instructors need to be cognizant of the level of clarity of representations used during instruction, and 3) instructors should help students learn how to interpret representations containing arrows.
\end{abstract}

\section{INTRODUCTION}

At its core, visual literacy involves the ability to comprehend and create visual representations (Trumbo, 1999; Schönborn and Anderson, 2006; Towns et al., 2012), a skill that professional scientists perform on a nearly daily basis. Mastery of the visual literacy skills within a discipline takes much practice. For example, performance-based assessments of early-career science, technology, engineering, and mathematics (STEM) graduate students reveal data analysis and the ability to draw conclusions from a data set are still developing in early-career graduate students (Timmerman et al., 2013). Interpreting results is a higher-order cognitive skill that requires making sense of graphs, plots, and other forms of visual representations of data. Because early-career graduate students still struggle with these skills, logic dictates that undergraduate students need even more opportunities to practice visual communication. This realization is articulated in the core competencies described in the Vision and Change in Undergraduate Biology Education report; visual literacy is included in the "Ability to Communicate and Collaborate with Other Disciplines" competency. In this report, experts call on instructors to create opportunities for students to practice formal and information communication, including visual communication (American Association for the Advancement of Science, 2011). Additionally, competencies and skills published for biochemistry and molecular biology undergraduate programs include visual literacy skills and the ability to communicate concepts and experimental data with visual representations (White et al., 2013). Though incorporating visual literacy skills into an already-packed biology curriculum
Kimberly Tanner, Monitoring Editor Submitted April 21, 2017; Revised November 30 , 2017; Accepted December 1, 2017

CBE Life Sci Educ March 1, 2018 17:ar6 DOI:10.1187/cbe.17-04-0069

*Address correspondence to: Dina L. Newman (dina.newman@arit.edu).

(c) 2018 L. K. Wright et al. CBE-Life Sciences Education $\odot 2018$ The American Society for Cell Biology. This article is distributed by The American Society for Cell Biology under license from the author(s). It is available to the public under an Attribution-Noncommercial-Share Alike 3.0 Unported Creative Commons License (http://creativecommons.org/licenses/ by-nc-sa/3.0).

"ASCB ${ }^{8}$ " and "The American Society for Cell Biology $\circledR^{\prime \prime}$ are registered trademarks of The American Society for Cell Biology. 
may be challenging, Airey and Linder (2009) illustrate the need to allow students to practice interpreting and creating visual representations. Furthermore, visual (external) representations can be a critical tool for allowing students to develop and practice scientific reasoning skills, because they provide something to reason about (Anderson et al., 2013).

Before students can successfully create and interpret scientific representations they must also be aware of the meanings of symbols and disciplinary-specific features of visual representations (Trumbo, 1999; Lowe, 2000), but the symbols are not always clear to students. For example, Schönborn et al. (2002) showed that biochemistry undergraduate students struggled to interpret a stylized diagram of immunoglobulin G (IgG) that illustrated its tertiary structure and variable, constant, and antibody-binding regions. The researchers concluded the main stumbling block was that students could not "decode" the symbolism used in the representation. They observed that circular shaded regions of IgG were mistaken for cells, and lines meant to represent structural information were mistaken for a DNA backbone or chemical bonds. Disciplinary experts can easily communicate with other experts through scientific representations, because experts speak the same language and are comfortable with the symbols and representations within their fields. Students, on the other hand, struggle to interpret scientific representations (Kozma and Russell, 1997; Kozma et al., 2000; Schönborn et al., 2002; Stieff et al., 2014; Stull and Hegarty, 2016), and the visual features become a roadblock to interpreting the information being conveyed (Ainsworth, 2006; Schönborn and Anderson, 2008; Roth and Pozzer-Ardenghi, 2013).

Unlike universal symbols for traffic, hospitals, or restrooms, scientific representations are sophisticated, complex, and not necessarily rooted in everyday objects and experiences familiar to the general public. One symbol that may cross the line between "everyday" and "scientific" is the arrow. Arrows in the everyday/ordinary world are used to show pedestrians the location of attractions, the direction in which to run on a jogging track, or the correct lane where an automobile driver must be. Arrows in science, however, are anything but simple. Our own research into student understanding of concepts related to genetic information flow has yielded important and interesting information into how students interpret canonical representations in molecular biology that involve arrows (Wright et al., 2014). Analysis of written responses and interviews revealed misconceptions students hold when interpreting the arrow between "DNA" and "RNA" in the traditional representation of the central dogma ("DNA $\rightarrow$ RNA $\rightarrow$ protein"). These findings helped inform the construction of a question on the Central Dogma Concept Inventory assessment tool that asked, "How is a region of double-stranded DNA molecule changed during the process of transcription?" (Newman et al., 2016). Further analysis showed that only $38 \%$ of students $(N=318,4$ different institutions, all postinstruction) correctly answered the question of how double-stranded DNA is changed during the process of transcription (unpublished data). Many students gravitate toward answers that involve chemical changes happening directly to the DNA: thymine bases are changed to uracil bases and/or the deoxyribose sugars of DNA are changed to ribose sugar groups found in RNA. We believe that this mental model of "DNA $\rightarrow$ RNA" representing a chemical change is generated and/or reinforced by the arrow, which makes the statement look like the symbolic representation of a chemical reaction that students have learned in their chemistry classes.

As articulated by Quillin and Thomas (2015), teaching and learning biology would be nearly impossible without the use of visual representations to make invisible, or nearly invisible, entities like atoms, molecules, forces, and energy come to life. While visual aids can be effective tools for simplifying complex processes and highlighting important aspects of biological phenomena, they are not without their shortcomings. Illustrations, and models in general, also have limitations, because they can only represent certain aspects of a concept (Linenberger and Bretz, 2012). Similar to our own work investigating students' interpretation of the transcription arrow in the central dogma expression ("DNA $\rightarrow$ RNA $\rightarrow$ protein"), others have found arrow symbols to be particularly confusing within the context of cardiac cycle diagrams and illustrations of nitrogen cycling in an ecosystem (Anderson et al., 2013).

To begin unpacking the phenomenon of representational competence, we decided to explore student understanding of figures that contained arrows. We chose to begin with introductory-level biology textbooks, because they are filled with arrow-containing representations, illustrations, and schematic diagrams. Unlike figures that appear in scientific articles, which experts use to communicate experimental data and results to other experts, figures in biology textbooks are meant to help teach students (novices) biology content. Students, who lack the representational competence and biology content knowledge of experts may struggle to use textbooks figures in a productive way, especially if the embedded symbolism is unclear. Unlike our previous work focusing on specific biology representations (Wright et al., 2014), in this work, we chose to explore the phenomenon of arrow symbolism usage and interpretation more broadly and not focus our attention on how students may (mis)interpret a particular type of symbol in a particular context. We did not focus our investigation into how biology experts interpret and use arrow symbols, because biology experts already have the knowledge and problem-solving strategies to decipher symbols within a figure or illustration. Because learners need more scaffolding to do or learn something new (Vygotsky, 1978), we wanted to investigate whether the arrow symbols in introductory biology textbook figures were clear to students and helpful for learning.

In this study, we sought to articulate the many styles of arrows and describe how they are used throughout a typical introductory biology textbook. We wanted to uncover patterns, if they existed, of style and meaning combinations used by illustrators throughout a textbook. We reasoned that set patterns of arrow style throughout a textbook might help learners decipher textbook figures, but first we needed to determine whether such patterns existed. We also explored how students interpreted arrow symbols within the context of textbook figures and looked for evidence that the arrows helped or hindered their understanding of the concept or process being illustrated. Finally, we analyzed results from an online survey designed to reveal whether certain arrow styles held inherent meaning for undergraduate students and aligned these data with results of our qualitative work.

\section{METHODS}

All human subjects research described here was reviewed and approved by the Rochester Institute of Technology's Internal Review Board. 


\section{Analysis of Arrow-Containing Figures from Introductory Biology Textbooks}

A first step of this research was an attempt to codify how arrows are used in a typical introductory biology textbook. Two researchers (P.L. and J.J.C.) identified all 1214 figures in a commonly used introductory biology textbook (Freeman et al., 2014; hereafter "Freeman"), 52\% (632) of which contained arrows. In total, 1387 arrows were analyzed for their style and meaning. Through discussion and consultation with the research group, the first researcher (P.L.) initially described 73 different meanings for arrows and 45 different arrow styles (see Supplemental Table 1). When the second researcher (J.J.C.) attempted to use the 73 definition arrow scheme for coding a subsection we found a high degree of disagreement. The whole group then took a closer look at the codes and realized the codes were too dependent on the level of biology content knowledge and experience of the coder. For example, a midlevel undergraduate researcher might describe a particular arrow as a "chemical reaction," while a more senior researcher coded the same arrow as a "phosphorylation," because she knew more about the underlying mechanism. These struggles made us realize how difficult it was for researchers to code arrow symbols based solely on what was being presented to the reader and not impart biology knowledge into the figure. This finding led us to reanalyze our 69 descriptive codes and think about how the descriptions could be part of broader, more conceptual categories. For example, "combination of gametic chromosomes," "results of a genetic cross at a phenotypic level," "generation advancement," and "independent assortment of alleles in gametes" could all be categorized as "flow of genetic information." Through discussion and debate, the research team was able to collapse and reorganize the descriptive codes into 12 conceptual codes (Table 1) that were then used for the final round of textbook figure coding. The revised coding scheme was more transparent and could be systematically applied to arrow symbols within biology textbook figures and was less dependent on the nuances that experts infer when deciphering biology textbook figures.

The conceptual categories could also be applied over the wide variety of topics and scales represented in introductory textbooks. For example, an arrow representation showing transcription of RNA from a DNA template and another arrow showing lateral gene transfer in a phylogeny both show a flow of information, but over different scales. Arrow styles were also collapsed into fewer categories-for example by ignoring subtle differences in arrow length or curvature. Arrow color was discounted as a unique feature; if a red arrow and a blue arrow were both the same shape, thickness, and relative size, they were coded as the same style. This strategy allowed us to create a coding strategy that was usable and robust. Not considering the color of the arrow symbol, however, did result in an underestimation of the actual number of unique arrow styles coded in the textbook figures. Using this new scheme, a team of three researchers (J.J.C., L.K.W., and D.L.N.) coded the arrows in two randomly selected figures from each of all 43 chapters of a different popular introductory biology textbook (Urry et al., 2016; hereafter "Campbell"). The randomly selected textbook figures were scanned, and images were imported into NVivo qualitative software for coding. Each unique arrow was coded for a conceptual category and a style category. All three coders made independent judgments on the meaning of each arrow symbol and then discussed each until consensus was reached. If the same arrow style was used to represent the same concept more than once within an individual figure, only of one of the arrows was counted in the analysis. A total of 230 unique arrows (21 different styles) in 86 figures were analyzed. Results were cross-tabulated in NVivo to discern patterns of arrow style linked with conceptual meaning.

TABLE 1. Description and examples of the conceptual coding categories used to categorize arrows in biology textbook figures

\begin{tabular}{|c|c|}
\hline Conceptual category & Description/examples \\
\hline Change over time & $\begin{array}{l}\text { Representation of change temporally: e.g., development of an organism over time; an evolutionary process; } \\
\text { one cell divides into two cells with no other details about the processes/inputs shown }\end{array}$ \\
\hline Change over distance & Representation of change spatially: e.g., an ion gradient; a gradient of an ecological factor \\
\hline Flow of information & $\begin{array}{l}\text { Movement of information from one entity to another: e.g., genetic information being passed from one } \\
\text { generation to the next or genetic information being passed from one cell to another; any central dogma } \\
\text { process }\end{array}$ \\
\hline Energy or matter transformation & $\begin{array}{l}\text { Any reaction involving a product and a reactant; a modification of a molecule resulting in its conformational } \\
\text { change; breaking of chemical bonds }\end{array}$ \\
\hline Movement & Any kind of motion, including locomotion and random motion \\
\hline Indication of a quantity or point & Emphasizing something specific for the reader to look at or notice within the figure \\
\hline Interaction/dissociation & $\begin{array}{l}\text { Two or more entities coming together or moving apart: e.g., a ligand binding with a receptor; a protein } \\
\text { binding/associating/dissociating with/from another protein }\end{array}$ \\
\hline External action applied & $\begin{array}{l}\text { Illustration contains an experimental step, something that happens as a result of an action outside of the } \\
\text { system: e.g., a computer program rearranges or aligns sequences (bioinformatics tools) }\end{array}$ \\
\hline Change in scale & $\begin{array}{l}\text { When two images are related because they are of the same fundamental thing: e.g., zooming in/out; a } \\
\text { cartoon illustration to a photograph; a math formula to a graphical representation }\end{array}$ \\
\hline $\begin{array}{l}\text { Directionality within an object or } \\
\text { system }\end{array}$ & $\begin{array}{l}\text { Illustration details the intrinsic orientation of something: e.g., the polarity of a molecule (i.e., DNA } 5^{\prime} \rightarrow 3^{\prime} \text { ); } \\
\text { the dorsal/ventral orientation of an organism }\end{array}$ \\
\hline Progression through a system & $\begin{array}{l}\text { Illustration shows linked processes without providing details: e.g., progression through named steps of } \\
\text { metabolism (i.e., glycolysis } \rightarrow \text { pyruvate oxidation } \rightarrow \text { citric acid cycle) }\end{array}$ \\
\hline Input/output & $\begin{array}{l}\text { Illustration shows an entity absorbing or expelling something without fundamentally disappearing itself: } \\
\text { e.g., an arrow representing the signal input that stimulates a signal transduction cascade with no details } \\
\text { of the reactions or molecular products }\end{array}$ \\
\hline
\end{tabular}


Online Survey about Intrinsic Meaning of Arrow Symbols

The next question we addressed was whether biology novices have preconceived ideas about what particular arrow styles would represent in a biology context. In preparation for developing content for an online survey, semistructured think-aloud interviews were conducted with 10 undergraduate students. Subjects were recruited from freshman- and sophomore-level biology laboratory courses and were all biology or biologyrelated majors. Research subjects were shown a series of textbook-like figures created by a biomedical illustration student. Subjects talked their way through what they thought each figure or arrow was representing. They were also asked to choose arrows from a list of 50 arrow styles to best represent concepts like movement, energy transfer, chemical reaction, cell injury, force, cycle, and pathways. If a subject felt that none of the arrow styles was appropriate, they were encouraged to draw their own arrow. Features of arrows (thickness of line, dashed vs. solid line, shading. etc.) were also discussed.

Using the feedback from the pilot interviews, we developed an online survey that incorporated common answers and themes from the pilot interviews. The online survey, administered through Qualtrics, contained two general types of questions. Subjects were shown a series of simple illustrations (e.g., two identically shaped objects with an arrow between them) in which the arrow style changed from image to image. Subjects were prompted by the following text: "If you were to encounter this diagram in a biology textbook, what would you think the arrow is describing?" Subjects were asked to pick from a list of 16 possibilities (e.g., time passing, chemical reaction, movement) the meaning that best aligned with a particular arrow symbol.

The second type of question asked participants to choose one of 10 different images of arrows that best aligned with a particular phenomenon. For example, one of the prompts read, "If you needed to pick an arrow to describe a concentration gradient, which arrow would you choose?" The research team deliberately created the survey illustrations to have as little context as possible to tease out arrow styles that might hold intrinsic meaning for survey respondents. The survey contained six demographic questions (e.g., "Are you an undergraduate student?," "Which biology courses have you completed?"), in addition to the 29 questions about arrows in biology figures. The survey was launched on various social media platforms targeting undergraduate students on campuses across the country. Subjects were given no incentives to complete the survey, and survey responses were completely anonymous. A total of 282 individuals completed the survey, with 232 of the participants (83\%) having taken at least one college-level biology course. After (self-reported) non-undergraduate individuals were removed, a total of 204 responses from undergraduate students remained. Not all participants answered all questions, but at least 133 students answered each question.

\section{Semistructured Interviews}

To understand how undergraduate students interpret arrow symbols in standard biology textbook illustrations/figures, we selected seven different figures from the two introductory biology textbooks (Freeman and Campbell). The research team chose figures that included multiple arrows that were illustrated by multiple styles (e.g., dashed vs. solid arrows, or curved vs. straight arrows; provided in Supplemental Figure 1). The research team discussed and agreed on the concepts being illustrated and the meaning of each arrow in each figure before interviews were conducted. The figures, along with figure legends, were included in a packet for research subjects to go through, one at a time, during the interview.

Fourteen new undergraduates volunteered to participate in think-aloud semistructured, individual interviews. Research subjects had varying levels of biology experience, ranging from nonmajors to senior life science majors. The students' biology experience was classified by approximating the number of years of college biology experience based on the courses they reported taking. The interview cohort included one student with no years of experience (a non-biology major with only high school biology experience), three with 1 year of college biology experience, five with 2 years of experience, one with 3 years of experience, and four with 4 years of experience.

During each interview the researcher (J.J.C.) presented one figure at a time and asked each subject to explain what s/he thought about the meaning of each arrow in the figure represented. The interviewer did not offer suggestions about what various arrows could represent but let the participants explain in their own words. During each exchange, additional questions were asked about the features of certain arrows (e.g., "Why do you think this arrow is red?"), which helped to encourage additional discourse about arrow styles and meanings. Subjects were permitted and encouraged to use the figure legends, prior knowledge, and internal context to answer the questions. Each interview was video-recorded and transcribed. Transcripts were analyzed and coded using NVivo qualitative software.

Because we hypothesized that biology learners may misinterpret arrow representations in visual representations, we specifically looked for instances of confusion during the interviews. Statements were coded as "incorrect" when the subject identified the meaning of an arrow in a way that was not consistent with the meaning determined by the research team. For example, a particular arrow representing the process of transcription might be misinterpreted as movement of an RNA molecule. Statements were coded as "explicit confusion" when subjects stated that they were unsure or unable to provide an answer and as "implicit confusion" when tone of voice or body language suggested confusion (e.g., a long pause before answering or a questioning tone).

\section{RESULTS \\ Different Styles of Arrows Are Used to Represent Many Different Concepts in Biology}

Preliminary analysis based on the original codebook (based on examination of the Freeman textbook) yielded no alignment of arrow style usage with particular meanings. All common arrow styles were associated with multiple meanings, and all common arrow meanings were associated with multiple styles. To confirm these conclusions, we redefined our meaning codes, as described in Table 1, and applied this new codebook to a new textbook (Campbell). All arrow symbols present in 86 figures (two per chapter) from the Campbell textbook were analyzed and coded. Although 230 unique arrows were coded in the 86 figures, many figures contained multiple arrows of the same type, resulting in more than double that number of 
TABLE 2. Arrow key showing each distinct style of arrow discovered by textbook analysis described and represented by a unique color

\begin{tabular}{|c|c|c|c|c|c|}
\hline Color (no.) & Description & Example & Color & Description & Example \\
\hline 1 & Thin, straight & & 12 & $\begin{array}{l}\text { Thin, merging (straight or } \\
\text { curved) }\end{array}$ & \\
\hline 2 & Thin, curved & & 13 & Merging block & \\
\hline 3 & Straight block & & 14 & Thin, branching & \\
\hline 4 & Curved block & & 15 & Block, branching & \\
\hline 5 & $\begin{array}{l}\text { Thin, straight, } \\
\text { dotted }\end{array}$ & & 16 & $\begin{array}{l}\text { Thin, curved, touching } \\
\text { another object }\end{array}$ & \\
\hline 6 & $\begin{array}{c}\text { Thin, curved, } \\
\text { dotted }\end{array}$ & & 17 & Circle of arrowheads & \\
\hline 7 & $\begin{array}{l}\text { Double line } \\
\text { with barbs }\end{array}$ & & 18 & $\begin{array}{l}\text { Open circle with single } \\
\text { arrowhead }\end{array}$ & \\
\hline 8 & $\begin{array}{c}\text { Thin, double } \\
\text { headed }\end{array}$ & & 19 & Jumping & \\
\hline 9 & $\begin{array}{l}\text { Double-headed } \\
\text { block }\end{array}$ & & 20 & Zigzag arrow & \\
\hline 10 & $\begin{array}{l}\text { Curved, } \\
\text { growing }\end{array}$ & & 21 & $\begin{array}{l}\text { Section of a circle of } \\
\text { arrowheads }\end{array}$ & \\
\hline 11 & $\begin{array}{l}\text { Curved, } \\
\text { shrinking }\end{array}$ & & & & \\
\hline
\end{tabular}

individual arrow symbols in the figures. This finding, in and of itself, is indicative of the expansive informational content found in a typical introductory biology textbook and how much illustrators rely on arrow symbols to demonstrate processes and/or concepts to students. In total, 21 different arrow styles were used in the 86 figures coded. As noted in the Methods section, the color of the arrow was not considered a distinguishing feature. Descriptions and examples of the different arrow styles are compiled in Table 2.

To illustrate how many different styles of arrows were used to represent each of the conceptual categories of meaning, we created a stacked bar graph (Figure 1). One of the most striking results of this analysis was the relative lack of consistency between arrow style and conceptual meaning. For example, the concept of movement was represented by 12 different arrow styles, input/output was represented by nine different arrow styles, and change over time and progression through a system were each represented by eight different arrow styles. Four styles (arrows 1, 2, 3, and 4) were used to represent nearly all 12 conceptual meanings, and the number of conceptual meanings for each arrow style varied widely (up to 11 different meanings per style). In other words, different styles were used to represent the same concept, and the same concept was represented by different arrow styles. As illustrated by Figure 1, arrow style 10 (curved, growing; see Table 2) was used most consistently throughout the textbook to represent the concept of a change in scale. However, other textbooks do not necessarily use this symbol exclusively to indicate a change 


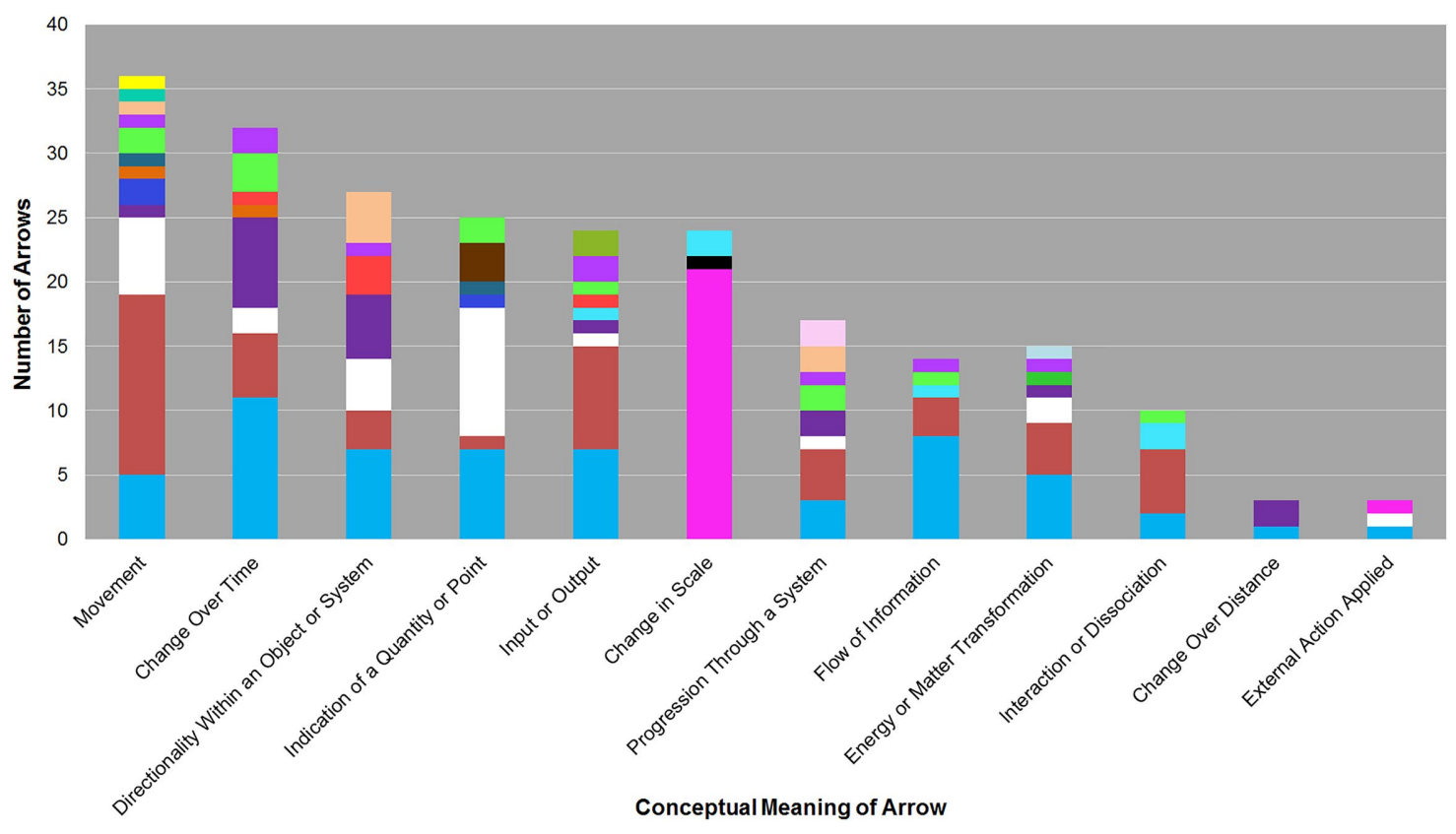

FIGURE 1. There is little consistency between style and conceptual meaning of arrow symbols used in a common introductory biology textbook (Campbell). A total of 86 figures, containing 230 unique arrows, were examined from the Campbell textbook. Arrows were coded based on style and conceptual meaning. The stacked bar graph represents the number of arrows of each style used to represent each conceptual meaning. Arrow style/color key is presented in Table 2.

in scale (unpublished data), so this was likely a conscious choice on the part of the publisher.

Introductory biology typically provides a sample of many subfields of biology, each of which has its own vocabulary and typical representations (e.g., signal transduction pathways in cell biology, gene networks in developmental biology, cladograms in evolutionary biology). Because introductory biology textbooks are organized by themes that correspond to these subfields, we hypothesized that there would be patterns of arrow style by textbook unit that were not apparent when the textbook was analyzed as a whole. Our initial findings told us that, overall, there were few patterns linking arrow style and meaning, but we wanted to investigate patterns that may be specific to content area. For example, the "Chemistry of Life" unit may contain a higher frequency of diagrams showing biomolecules and chemical reactions compared with the "Evolution" unit, so frequencies of certain arrows may align with certain units. Using NVivo, a cross-tabulation of arrow style and meaning was performed on each unit of the textbook. A density dot plot was created as a way to visualize variations or patterns within individual units as well as throughout the textbook (Figure 2). Few such patterns were discovered. The concept of "change in scale" was still represented by a curved, growing arrow (style 10) throughout each unit, and most other styles were found in most units with little correlation to conceptual meaning.

\section{Few Arrow Styles Have Inherent Meaning to Undergraduate Students}

We created online survey questions to probe student thinking about whether certain styles of arrows held intrinsic meaning to undergraduate students. In eight of the online survey questions, respondents were shown a figure containing one arrow between two identical shapes. Respondents were prompted by the text, "If you were to encounter this diagram in a biology textbook, what do you think the arrow is describing?" Participants chose one of 10 different meanings from a list. Table 3 illustrates each image and the four meanings that were chosen by the greatest percentage of respondents. Only three arrow styles seemed to carry inherent meaning for the majority of survey respondents. For most survey respondents, an " $X$ " through a line arrow meant "inhibition of a chemical reaction"; a gradient-shaded block arrow meant "concentration gradient"; and multiple, small block arrows meant "multiple steps." The remainder of the arrow symbols had no apparent inherent meaning for students.

In another set of survey questions, participants were asked to select one arrow style from six different choices that they felt best matched a particular concept or process. For example, "If you needed to pick an arrow to describe a concentration gradient, which arrow would you choose?" Table 4 reveals how survey participants responded to the survey prompts. Respondents had strong feelings about how to represent a concentration gradient or the emission of light, but little agreement on how to best represent movement. Interestingly, more than half of participants chose a curved arrow to represent a step of an ecosystem cycle.

\section{The Meaning of an Arrow May Depend on Other Arrows in the Same Figure}

One interesting finding from our analysis of survey data was that arrow meaning could change, depending on the style of another arrow in the same figure. As shown in Table 3, a simple 


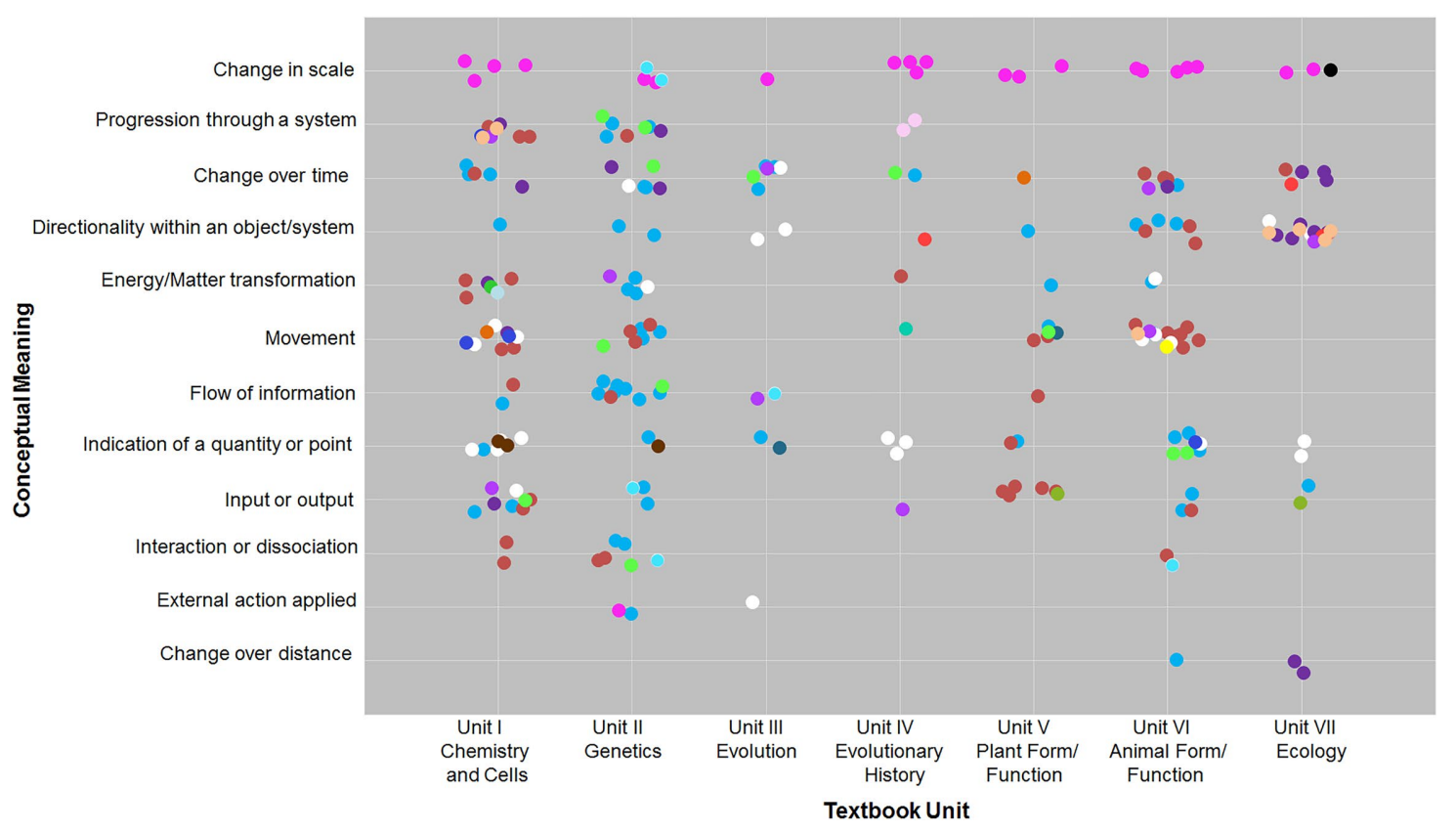

FIGURE 2. There is little consistency in the style of arrows used within each unit of an introductory biology textbook. A total of 86 figures, containing 230 unique arrows, were examined from the Campbell textbook. Arrows were coded based on style and conceptual meaning. Each dot represents one arrow, and the color of the dot corresponds to arrow style. Arrow style/color key is presented in Table 2.

linear arrow had no consistent interpretation when there was no context for survey participants to look to for clues. However, when this arrow was juxtaposed with another arrow in the same figure, the meaning of the original arrow changed to align with the meaning of the new arrow. Figure 3 shows the survey images: the first arrow was a thin, straight arrow, while the second was a thin, dotted arrow (Figure 3A), a line of multiple, small arrows (Figure 3B), or a thin, curved arrow (Figure 3C). Given the same set of possible meanings, the top choice for the meaning of the thin, straight arrow changed in each case. In Figure 3A, 64\% of the users identified the dotted arrow with "uncertain outcome," while the straight arrow meant "certain outcome" for $53 \%$ of the respondents. In Figure 3B, $61 \%$ of the users identified the line of small multiple arrows to represent "multiple steps," and the top choice for the straight arrow became "single step" (43\% of responses). In Figure 3C, the topranked choice for the thin, curved arrow related to chemical reactions (38\%), and the top choice for the thin, straight arrow also became "chemical reaction" ( $41 \%$ of responses). Interestingly, a single straight arrow alone in a figure had no particularly strong correlation to any of the choices of conceptual meanings.

\section{The Meaning of Arrows in Biology Textbook Figures Is Not Explicit to Students}

To investigate how undergraduate students decipher arrow representations in biology textbook figures, we conducted semistructured interviews with 14 undergraduate students. All subjects were presented with the same seven figures. After analysis of all interview transcripts, we found that all interview subjects experienced at least some amount of confusion regarding the meanings of the arrow symbols presented in actual textbook figures. We would like to point out that we cannot say the arrow symbols were the sole cause of confusion in our student interview subjects. However, we can provide evidence that the arrow symbols did not help the subjects decipher the content or processes illustrated by the figures. Evidence of confusion during the interviews was documented in one of three ways: incorrect response, explicit confusion, or implicit confusion.

Responses were coded as "incorrect" when the subject described a meaning of an arrow in a way that did not match how the research team defined the arrow; 100\% of the interviews had at least one instance of a subject incorrectly interpreting an arrow symbol (Table 5). For example, one figure from Campbell (Supplemental Figure 1B) contains a straight arrow that extends from a $\mathrm{G}$ protein-coupled receptor to an activated $\mathrm{G}$ protein, indicating the activation step in the signal transduction cascade. While not all undergraduate biology students have a deep understanding of signal transduction cascades and $G$ protein-coupled receptors, we argue that the arrow symbols in the diagrams do not appear to help them decipher the process. While some of the research subjects described the arrow in a correct way such as

Um, I think it shows, like, the beginning step of like the cascade where I think binding of the ligand receptor would induce the $\mathrm{G}$ protein to, I believe, hydrolyze the GTP.

Other, incorrect, interpretations included ideas of a chemical reaction, resulting in one protein being changed or modified into something else such as

I guess it's [the receptor protein] being turned into this, G protein? That is kind of a [pause] reaction arrow-looking thing to me. Something [pause] is changing from one reactant to a product. 
TABLE 3. Few arrow styles have inherent meaning for students

\begin{tabular}{|c|c|c|c|c|c|}
\hline Arrow diagram & $n^{\mathrm{a}}$ & First highest choice & Second highest choice & Third highest choice & Fourth highest choice \\
\hline & 198 & $\begin{array}{l}\text { Single step } \\
32.83 \%\end{array}$ & $\begin{array}{l}\text { Chemical reaction } \\
17.68 \%\end{array}$ & $\begin{array}{l}\text { Certain outcome } \\
15.15 \%\end{array}$ & $\begin{array}{l}\text { Time passing } \\
13.13 \%\end{array}$ \\
\hline & 194 & $\begin{array}{l}\text { Multiple steps } \\
48.97 \%\end{array}$ & $\begin{array}{l}\text { Time passing } \\
19.07 \%\end{array}$ & $\begin{array}{l}\text { Movement in a particular } \\
\quad \text { direction } \\
5.15 \%\end{array}$ & $\begin{array}{l}\text { Certain outcome } \\
5.15 \%\end{array}$ \\
\hline & 189 & $\begin{array}{l}\text { Inhibition of a chemical } \\
\text { reaction } \\
65.00 \%^{\text {b }}\end{array}$ & $\begin{array}{l}\text { Uncertain outcome } \\
16.93 \%\end{array}$ & $\begin{array}{l}\text { Negative consequence } \\
13.76 \%\end{array}$ & $\begin{array}{l}\text { Certain outcome } \\
2.12 \%\end{array}$ \\
\hline & 181 & $\begin{array}{l}\text { Time passing } \\
27.62 \%\end{array}$ & $\begin{array}{l}\text { Uncertain outcome } \\
24.86 \%\end{array}$ & $\begin{array}{l}\text { Movement in a particular } \\
\quad \text { direction } \\
16.02 \%\end{array}$ & $\begin{array}{l}\text { Multiple steps } \\
6.08 \%\end{array}$ \\
\hline & 173 & $\begin{array}{l}\text { Concentration gradient } \\
\mathbf{5 8 . 9 6 \%}\end{array}$ & $\begin{array}{l}\text { Time passing } \\
8.09 \%\end{array}$ & $\begin{array}{l}\text { Certain outcome } \\
5.78 \%\end{array}$ & $\begin{array}{l}\text { Movement in a particular } \\
\text { direction } \\
5.20 \%\end{array}$ \\
\hline & 169 & $\begin{array}{l}\text { Multiple steps } \\
\mathbf{7 2 . 7 8 \%}\end{array}$ & $\begin{array}{l}\text { Movement in a } \\
\text { particular direction } \\
10.06 \%\end{array}$ & $\begin{array}{l}\text { Time passing } \\
7.69 \%\end{array}$ & $\begin{array}{l}\text { All other choices } \\
<2 \%\end{array}$ \\
\hline & 163 & $\begin{array}{l}\text { Movement in a particular } \\
\quad \text { direction } \\
23.31 \%\end{array}$ & $\begin{array}{l}\text { Uncertain outcome } \\
19.02 \%\end{array}$ & $\begin{array}{l}\text { Multiple steps } \\
11.04 \%\end{array}$ & $\begin{array}{l}\text { Evolution } \\
11.04 \%\end{array}$ \\
\hline & 157 & $\begin{array}{l}\text { Physical interaction/ } \\
\text { binding } \\
25.17 \%\end{array}$ & $\begin{array}{l}\text { Movement in a } \\
\text { particular direction } \\
16.08 \%\end{array}$ & $\begin{array}{l}\text { Chemical reaction } \\
13.99 \%\end{array}$ & $\begin{array}{l}\text { Stimulation of a chemical } \\
\text { reaction } \\
9.09 \%\end{array}$ \\
\hline
\end{tabular}

aTotal number of survey respondents for the question.

${ }^{\mathrm{b}}$ Boldface indicates selection by more than half of the participants.

Another student seemed to confuse this process with electron transport:

I would say just maybe electron transfer going from the $G$ protein-coupled receptor to the G protein that has the GTP.

One admittedly complex figure about cell cycle inhibition pathways (Supplemental Figure 1D) provided interesting data from interview subjects and further evidence that arrows symbols in biology illustrations do not always help learners decipher concepts or processes. In this figure, UV light (indicated by a bright yellow zigzag arrow) was shown to induce a double-stranded break to a DNA helix. A short, curved arrow led from the DNA to a series of oval shapes, labeled protein kinases. An identical short, curved arrow led from the protein kinases to an irregularly shaped structure labeled "activated form of p53." The research team interpreted this figure as an illustration of how a DNA damage event can trigger activation of an intracellular protein kinase cascade. The cascade ends with the activation of p53 protein, which then binds to DNA to induce expression of (eventual) protein that inhibits the cell cycle. Students described the meaning of the short, curved arrows leading from the damaged DNA to the protein kinases in a variety of ways. To some students, the arrow indicated that the protein kinases were originally physically interacting with/on the DNA helix and then moved off the DNA as a result of the damage:

Umm ... DNA is damaged and so these protein kinases um ... sort of are a result of the damage and come off of the, the DNA structure 
TABLE 4. Top responses of students when asked on a survey to choose the best arrow to represent the concept

Concept

NA: Only seven people chose any option other than the top two, and they were scattered among several options.

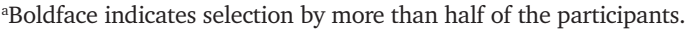

Another subject thought the curved arrows were indicative of central dogma processes and the damaged DNA region was the location of the gene encoding the protein kinase used in the cascade.

That's DNA being transcribed and translated into protein kinase and then protein kinase is going through and activating p53.

A different student realized that an interaction between the protein kinases and p53 was necessary for activation of p53 (which is true), but the type of arrow used did not allow this student to understand that a phosphorylation event was necessary to activate p53. The student thought simple interaction between proteins was sufficient for activation.

It shows the result after these kinases, um, touch the active form of $\mathrm{p} 53$, and this shows that if this were to touch, this then this would be the result.

Finally, another student subject thought the arrows were representative of some process but could not make the connection between the DNA damage and activation of a protein cascade.

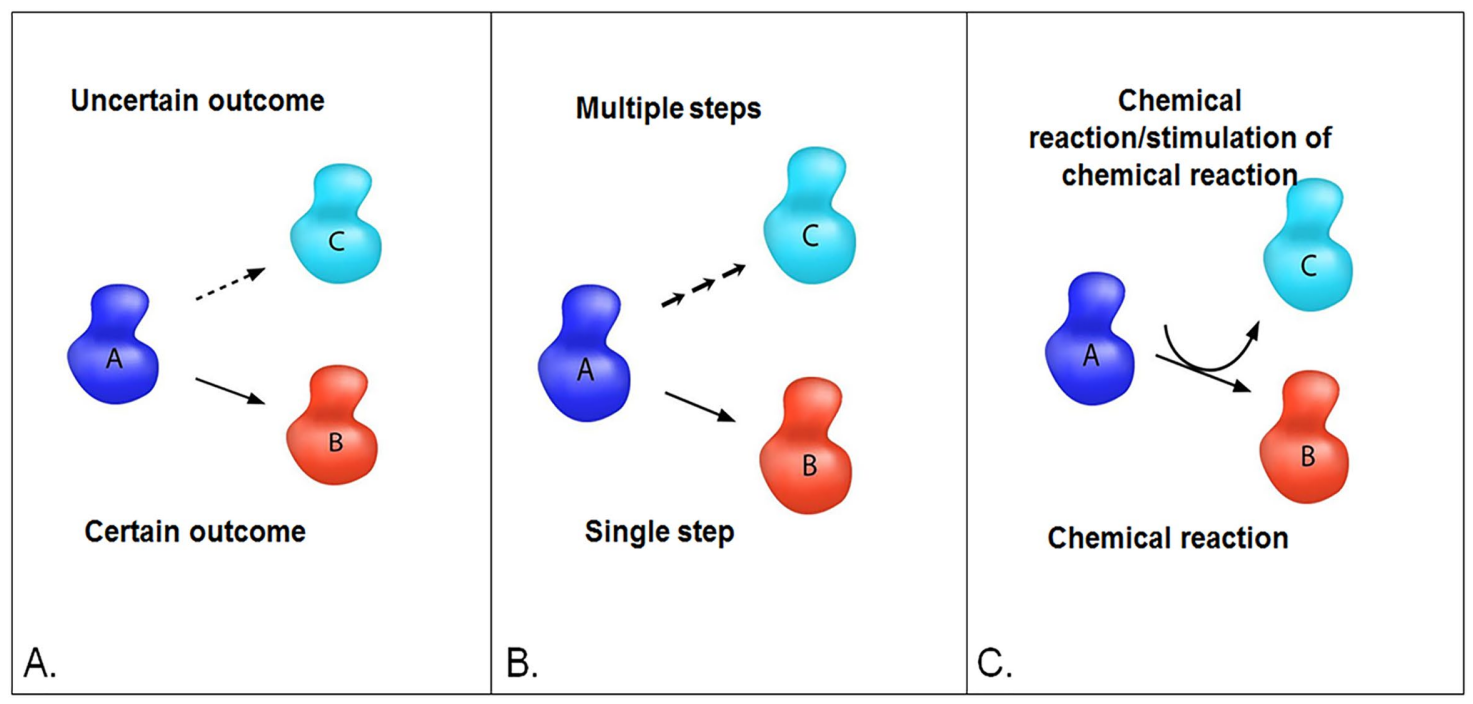

FIGURE 3. The meaning of one arrow may depend on other types of arrows appearing in the same figure. The online survey contained three different figures that juxtaposed different arrow styles with a thin, straight arrow: (A) dotted arrow; (B) series of multiple arrows; and (C) thin, curved arrow touching the straight arrow. 
TABLE 5. Indications of confusion from within individual interviews

\begin{tabular}{lcc}
\hline Theme & $\begin{array}{c}\text { Proportion of } \\
\text { interviews } \\
\text { containing theme }\end{array}$ & $\begin{array}{c}\text { Average } \\
\text { occurrences per }^{\mathrm{a}}\end{array}$ \\
interview $^{\mathrm{b}}$
\end{tabular}

${ }^{a}$ Calculated from the total number of interviews conducted $(n=14)$.

betermined by taking the total occurrences of a given code divided by the number of interviews containing the code.

I guess it, maybe, is showing a process. From the DNA damage or whatever to a mutation. I'm not sure why they have these little green circles.

When interpreting figures, research subjects also demonstrated confusion by saying, "I don't know" or "This is a confusing arrow" or demonstrated confusion by long pauses and hesitation. Here are two quotes from different students:

I'm sure it [arrow] is trying to show a connection between these two things [two different conformations of a protein], I forget what they're called. But it doesn't really show what it's doing. It just seems like a random arrow [in reference to Supplemental Figure 1E].

That one also looks like a step, but then it's confusing because there's not an arrow directly from this to go on to the next step, so that's confusing [in reference to Supplemental Figure 1B].

We originally hypothesized that students with more biology experience might have a better grasp on the conceptual meaning of the arrows presented to them during the interview, but this was not supported by the data. In this small sample $(n=$ 14), more experienced students did not necessarily demonstrate less confusion or have more correct answers than less experienced students.

In parallel to our findings from the survey (Figure 3A), the idea of "less strong" or "less certain" came up during the interviews, especially when a dashed arrow appeared in the same figure as a solid line arrow (Supplemental Figure 1F). In this figure, a dashed, straight arrow was used between the text "glucose" and "2 Pyruvate" in a representation of a metabolic pathway. The text "Glycolysis" appeared above the dashed arrow as a label for the process. The research team agreed that the dashed arrow was meant to represent the many steps of glycolysis, but some of our interviewees extracted a different meaning:

Okay, so I think dotted means also variable, because glucose can go through many cycles, so if it's going through glycolysis, this is what will happen.

In this quote we believe the word "variable" was intended to mean "unknown" or "uncertain in nature." Because this is not how biologists would ever describe glycolysis, we suggest that prior "everyday" experiences may have shaped this student's idea that a dashed line is meant to imply something less certain than a solid line symbol would.

\section{The Style of the Arrow May Lead Students Astray}

In both question formats on the survey (i.e., "What does this arrow mean?" and "Which arrow would you use to represent this?"), the majority of participants indicated that a shaded block arrow signified the concept of a concentration gradient. What happens, then, when a shaded arrow is used to depict something other than a concentration gradient? Another figure used to probe students during interviews (Supplemental Figure 1C) included four shaded block arrows. These arrows were meant to indicate the direction of proton movement through membrane-embedded protein complexes from the matrix to the intermembrane space in the mitochondria. Coincidentally, three of the four arrows were positioned so the shading of the arrow did align with the proton gradient on either side of the inner mitochondrial membrane. But the shading of the fourth arrow, pointing the opposite way, also went in the opposite direction of the proton gradient, so it could not possibly have signified the gradient. Six of the 14 interviewees correctly described the shaded block arrows as representing movement of protons, but the other eight students described the arrows as representing a concentration gradient only (2/14), both movement and a concentration gradient simultaneously (4/14), or movement with/against/of a concentration gradient (2/14). In other words, even though most students felt the shaded block arrow had something to do with movement, eight out of 14 also assumed shading illustrated a gradient. We argue that this is a case in which the arrow may either mislead students about the biological phenomenon and/ or increase the cognitive load on learners as they reconcile the backward shading with the actual proton gradient.

In another example, students were shown a figure depicting a sodium-potassium pump protein embedded in a membrane in two different conformations (Supplemental Figure 1E). A double-headed block arrow was inserted between each conformation of the protein to indicate switching between conformations by the protein. The two conformations were represented by dramatically differently shaped green blobs, one with three binding pockets (for $\mathrm{Na}^{+}$) and the other with two binding sites (for $\mathrm{K}^{+}$), and a straight arrow running through the center of each blob, showing the directions of ion movement facilitated by the pump $\left(\mathrm{Na}^{+}\right.$out of the cell, $\mathrm{K}^{+}$into the cell). During the interviews, only seven of 14 students (50\%) correctly identified the double-headed arrow as depicting a conformational change. A correct answer is illustrated by the following exchange:

Interviewer: And then how about that green arrow [double headed] there?

Student: Uh, that's showing the conformation change where this form sends sodium out of the cell and this form brings potassium into the cell.

Interviewer: And so would you say the two green things are the same or different?

Student: They appear to be the same, just different conformations of the same molecule.

Many students showed confusion when asked specifically about the double-headed arrow and often assumed it illustrated movement-either movement of the phospholipids within a membrane or diffusion/movement of two distinct proteins, as demonstrated by answers of these students when asked about the meaning of that arrow: 
Like these [proteins] can switch spots and it's not a big deal.

[Pause] That-I have no idea. Maybe they're moving or something? Or like they switch roles maybe?

[Pause] I'm not too sure, but I would say maybe the fluidity of the membrane?

One research subject even changed his correct mental model $\left(\mathrm{Na}^{+} / \mathrm{K}^{+}\right.$pump is a single protein) to an incorrect one (it is composed of two distinct proteins) after viewing the figure. Here is his response to a question about the meaning of the double-headed arrow:

[Pause] I'm not really sure. Um, I know there's the sodiumpotassium pump, but I've always seen it as like, one molecule. Um, maybe it suggests that they work together?

Again, we cannot say with certainty that the arrow itself was the sole cause of confusion in this figure, but our interviews certainly do provide evidence that arrows used in biology textbook figures are not always helpful to biology learners.

\section{DISCUSSION}

The field of biology encompasses a large array of subfields. Scientists in disciplines such as ecology, molecular biology, developmental biology, and physiology are all biologists, even though the language and visual representations they use may vary widely. Practitioners in all subfields of biology, though, use arrow symbols in at least some aspects of their visual representations. The same arrow symbols may represent chemical reactions, conformational change, or metabolic pathways in biochemistry; direction of a gradient, movement of a solute, or signal transduction in cell biology; direction of blood flow, movement through a system, or paracrine signaling in physiology; interactions between species, direction of migration, or energy flow in ecology; and passage of time, gene flow, or speciation in evolutionary biology. Regardless of arrow style, experts probably have little difficulty correctly interpreting a figure. In other words, biology experts may occasionally find a textbook illustration or diagram that incorporates confusing symbols or representations, but because they are already familiar with the content, the symbol is not a barrier to understanding. Novices, on the other hand, are still learning the discipline and the visual language; they cannot easily fall back on content knowledge to help decipher a figure or illustration, because they may not have a deep enough grasp of the material in the first place. This "catch-22" is an interesting and complicated problem in biology education. How do educators teach students to decipher representations about biology content when the students are still learning the content? Learners must use visual representations to help fill in the gaps of their own mental models of scientific processes, but if the symbols used are more confusing than helpful, learning is not achieved (Roth and PozzerArdenghi, 2013).

Arrow representations are extremely common in biology textbook representations. Because there is no standard language for arrow usage in biology, the burden for choosing an arrow style for a textbook figure largely falls on the illustrator(s). Color and/or style of arrow may be determined by the overall aesthetics of a textbook or a "look" that the publisher is trying to achieve. Because the figures and the symbols within the representations contain little hidden or unclear information to experts, who are also the writers and reviewers, textbooks continue to be published with representations that students cannot interpret.

Our work investigating how arrows are used in biology illustrations and figures highlights several important findings that we summarize here and expand on below.

\section{The style of arrow representations in an introductory} biology textbook do not align with conceptual meaning. A number of different arrow styles were used to depict the same meaning, and the same arrow style was used to depict a number of conceptual meanings (Figure 1). There is also little consistency of patterns within individual units of the book (Figure 2).

2. Few arrow styles have inherent meaning for students. An online survey revealed that most arrows, when taken out of the context of a content-laden illustration or figure, carry little meaning for undergraduate students (Tables 4 and 5). While not surprising, this finding suggests that learners may struggle to make sense of biology illustrations, because they have to look for clues elsewhere in the diagram and cannot rely on a predetermined key for arrow symbology.

3. The inferred meaning of one arrow may be dependent on how other arrows in the same diagram are styled. Survey respondents altered their interpretation of arrow symbols depending on what other arrow symbols also appeared in the figure (Figure 3). Here, we suggest that, like new readers looking for context clues when deciphering text, biology learners will also look for clues when deciphering symbols.

4. Undergraduates demonstrate confusion when deciphering arrow representations in textbook figures. Interviews with undergraduate students revealed all students experienced confusion when interpreting arrow symbols embedded in textbook figures (Table 5), and qualitative analysis revealed multiple examples of this confusion.

\section{Implications for Teaching and Future Research}

On the basis of our analyses of two college-level biology textbooks, data from a large online survey, and in-depth interviews with undergraduate students, we suggest that instructors need to spend time teaching students to deconstruct visual representations. The data we presented support our hypothesis that arrow symbols are confusing to undergraduates, regardless of their biology experience. Students may experience cognitive overload when trying to decipher figures, especially when a single figure contains a variety of arrow styles and meanings. While it is not possible to critically evaluate every figure in a biology textbook, instructors could incorporate opportunities for students to practice analyzing arrow-containing visual representations in class. Instructors should also be aware of the expert-novice divide when creating and using classroom materials. For example, experts know that the arrows found in ribbon diagrams of protein structure confer meaning about the directionality and structure of the protein. Students, on the 
other hand, may see arrows as decorative features (Offerdahl et al., 2017).

Our findings highlight the fact that textbook publishers and editors do not necessarily have a predetermined scheme for how arrow representations will be used throughout a textbook, a textbook section, or even within a figure itself. In fact, textbook publishers may rely on a number of illustrators, so instructors should not assume a set style of arrows will be used consistently. We found that a few arrow styles did carry intrinsic meaning for students in our test population. Most students associated an arrow with an "X" through its tail with the concept of inhibition, a thin, wavy arrow with the concept of light energy, and a shaded block arrow with the concept of a concentration gradient. Circular arrows were chosen to represent steps in a cycle, which also makes sense from a conceptual standpoint; cycles, like circles, are continuous. Instructors, and illustrators, should be aware of these ideas and use arrow symbols in a way that agrees with students' associations, if possible. For example, instructors and illustrators should not use a shaded block arrow to represent anything but a concentration gradient, because students will infer a concentration gradient regardless of the intent of the arrow. Many students will also infer a chemical reaction when presented with a thin, straight arrow. This was the most commonly used arrow style in both of the textbooks we used for our analysis, but it was used to represent much more than energy/matter transformations. Instructors may see thin, straight arrows as representing steps in a signal transduction cascade, for instance, but students might look at the figure and see receptor ligand complexes being converted into activated G proteins (as was revealed in our interviews). Instructors and illustrators may consider incorporating a key to at least point students in the right direction when using visual representations. Incidentally, only five of the 718 figures reviewed in this work (less than 1\%) contained a key.

Because biology students are still learning concepts and content, they may need to look for additional clues to help them decipher visual representations. We find the conceptual reasoning mode (CRM) framework (Schönborn and Anderson, 2008) to be a helpful resource for investigating how students may use external representations for learning. The CRM model recognizes the importance of both reasoning strategies (R) and mode (M; the features of the actual diagram or illustration) as the user attempts to make sense of an external representation. This intersection is referred to as "R-M" in the CRM conceptual model. Ideally, the mode will be synergistic with students' reasoning strategies, but this may not always be the case. For instance, pattern recognition and "compare and contrast" approaches are important reasoning strategies for scientists, but they can lead students astray when interpreting poorly drawn scientific figures. In our study, we observed that the inferred meaning of an arrow could change, depending on what other arrow style was next to it in the same figure. In other words, the students were ascribing meanings to two different arrows based on the differences in the superficial aspects of the symbols (dashed vs. solid, curved vs. straight, etc.). A dashed arrow compared with a solid arrow was perceived as "uncertain," while the solid arrow meant "certain outcome." Multiple small arrows in a row meant "many steps" when used next to one solid arrow, which then meant "single step" to them. This is a well-known phenomenon in the field of cognitive science, where researchers have found that contrasts facilitate people noticing features they might otherwise miss (Bransford et al., 1989). Thus, it is important to leverage student reasoning in a productive way and not to work against it.

Our work revealed other instances in which the representation mode does not support reasoning strategies, resulting in poor comprehension of a scientific diagram. In an illustration of genetic information flow, the same style of arrow was used to represent both the process of transcription and the movement of the mRNA product. Learners may reason that identical symbols should illustrate the same processes or concepts, but we found textbook figures do not always abide by this principle of synonymy. When similarly styled symbols are used for different purposes, they cause confusion for the learner (Ametller and Pintó, 2002). Our work also revealed instances of polysemy, when differently styled arrows are used to represent the same concept or process (Strömdahl, 2012). Polysemy can result in learners having to discover a new meaning for the same symbol, sometimes within the same figure, which is also confusing. Thus, instructors and illustrators should be cognizant of how superficial aspects of arrow symbols may be perceived by learners and be especially careful when juxtaposing two (or more) different styles of arrows in the same figure.

\section{Future Work}

While there is still much to investigate, we feel that this work is an important step into better understanding how students interpret and use symbolism in biology representations. Our research shows we need to clarify hidden meanings within arrow symbols for biology learners and help familiarize them with the norms and symbols of the field. While a fully agreedupon language of arrow symbols does not exist in biology, there are some common representations that we expect would be recognizable to an expert. For example, substrate-level phosphorylation is typically shown by a curved arrow that appears to "bounce" off the substrate. Now that we have described the phenomenon, it will be interesting to expand our work and include expert ideas and interpretations of arrow symbols used in biology textbook figures.

Future work will also involve collaboration with biomedical illustrators and visual communication experts to articulate principles of best practices when incorporating arrows in biology representations. We envision a new framework that will guide future illustrators and educators on how to best incorporate symbolism (such as arrows) into visual representations for biology learners. This framework will leverage principles of visual communication with research-based strategies of effective learning to improve both design of figures by professionals and interpretation of figures by students. In the long term, we hope that this work will encourage practicing biologists to begin to be more intentional about how they incorporate symbolism in their communications with each other, such as when creating figures for journal articles. If we teach today's students to think about visual communication, then hopefully they will take the principles they learned in the classroom into the "real world" of science and improve communication there too. 


\section{ACKNOWLEDGMENTS}

We thank Sarah Deaton for developing the online survey and Jim Perkins for practical insight into the field of biomedical illustration. Azam Fikri Taifor, Andy Lu, and Katie Lewis contributed to early attempts at defining arrow meanings and coding textbook figures. This work was supported by a National Science Foundation grant (DUE-1359262) and an internal grant from the Rochester Institute of Technology College of Science (Dean's Research Initiation Grant).

\section{REFERENCES}

Ainsworth, S. (2006). DeFT: A conceptual framework for considering learning with multiple representations. Learning and Instruction, 16, 183-198.

Airey, J., \& Linder, C. (2009). A disciplinary discourse perspective on university science learning: Achieving fluency in a critical constellation of modes. Journal of Research in Science Teaching, 46, 27-49.

American Association for the Advancement of Science (2011). Vision and change in undergraduate biology education: A call to action. Washington, DC.

Ametller, J., \& Pintó, R. (2002). Students' reading of innovative images of energy at secondary school level. International Journal of Science Education, 24, 285-312

Anderson, T. R., Schönborn, K. J., du Plessis, L., Gupthar, A. S., \& Hull, T. L. (2013). Identifying and developing students' ability to reason with concepts and representations in biology. In Treagust, D. F., \& Tsui, C.-Y. (Eds.) Multiple representations in biological education (pp. 19-38). Dordrecht, Netherlands: Springer.

Bransford, J. D., Franks, J. J., Vye, N. J., \& Sherwood, R. D. (1989). New approaches to instruction: Because wisdom can't be told. In Vosniadou, S., \& Ortony, A. (Eds.), Similarity and analogical reasoning (p. 470). Cambridge, UK: Cambridge University Press.

Freeman, S., Allison, L., Black, M., Podgorski, G., Quillin, K., Monroe, J., \& Taylor, E. (2014). Biological science. Boston: Pearson.

Kozma, R., Chin, E., Russell, J., \& Marx, N. (2000). The roles of representations and tools in the chemistry laboratory and their implications for chemistry learning. Journal of the Learning Sciences, 9, 105-143.

Kozma, R. B., \& Russell, J. (1997). Multimedia and understanding : Expert and novice responses to different representations of chemical phenomena. Journal of Research in Science Teaching, 34, 949-968.

Linenberger, K. J., \& Bretz, S. L. (2012). Generating cognitive dissonance in student interviews through multiple representations. Chemistry Education Research and Practice, 13, 172-178.

Lowe, R. (2000). Visual literacy in science and technology education. Connect: UNESCO International Science, Technology and Environment Education Newsletter, 25(16), 1-3.
Newman, D. L., Snyder, C. W., Fisk, J. N., \& Wright, L. K. (2016). Development of the Central Dogma Concept Inventory (CDCI) assessment tool. CBELife Sciences Education, 15, ar9.

Offerdahl, E. G., Arneson, J. B., \& Byrne, N. (2017). Lighten the load: Scaffolding visual literacy in biochemistry and molecular biology. CBELife Sciences Education, 16, es1.

Quillin, K., \& Thomas, S. (2015). Drawing-to-learn: A framework for using drawings to promote model-based reasoning in biology. CBE-Life Sciences Education, 14, 1-16.

Roth, W.-M., \& Pozzer-Ardenghi, L. (2013). Pictures in biology education. In Treagust, D. F., \& Tsui, C.-Y. (Eds.), Multiple representations in biological education (pp. 39-53). Dordrecht, Netherlands: Springer

Schönborn, K. J., \& Anderson, T. R. (2006). The importance of visual literacy in the education of biochemists. Biochemistry and Molecular Biology Education, 34, 94-102.

Schönborn, K. J., \& Anderson, T. R. (2008). A model of factors determining students' ability to interpret external representations in biochemistry. International Journal of Science Education, 31, 193-232.

Schönborn, K. J., Anderson, T. R., \& Grayson, D. J. (2002). Student difficulties with the interpretation of a textbook diagram of immunoglobulin $\mathrm{G}(\mathrm{lgG})$ Biochemistry and Molecular Biology Education, 30, 93-97.

Stieff, M., Lira, M., \& DeSutter, D. (2014). Representational competence and spatial thinking in STEM. Proceedings of International Conference of the Learning Sciences, ICLS, 2, 987-991.

Strömdahl, H. R. (2012). On discerning critical elements, relationships and shifts in attaining scientific terms: The challenge of polysemy/homonymy and reference. Science and Education, 21, 55-85

Stull, A. T., \& Hegarty, M. (2016). Model manipulation and learning: Fostering representational competence with virtual and concrete models. Journal of Educational Psychology, 108, 509-527.

Timmerman, B. C., Feldon, D., Maher, M., Strickland, D., \& Gilmore, J. (2013). Performance-based assessment of graduate student research skills: Timing, trajectory, and potential thresholds. Studies in Higher Education, 38, 693-710.

Towns, M. H., Raker, J. R., Becker, N., Harle, M., \& Sutcliffe, J. (2012). The biochemistry tetrahedron and the development of the taxonomy of biochemistry external representations (TOBER). Chemistry Education Research and Practice, 13, 296-306.

Trumbo, J. (1999). Visual literacy and science communication. Science Communication, 20, 409-425.

Urry, L. A., Cain, M. L., Wasserman, S. A., Minorsky, P. V., \& Reece, J. B. (2016) Campbell: Biology in focus. Pearson.

Vygotsky, L. S. (1978). Mind in society: The development of higher psychological processes. Cambridge, MA: Harvard University Press.

White, H. B., Benore, M. A., Sumter, T. F., Caldwell, B. D., \& Bell, E. (2013). What skills should students of undergraduate biochemistry and molecular biology programs have upon graduation? Biochemistry and Molecular Biology Education, 41, 297-301.

Wright, L. K., Fisk, J. N., \& Newman, D. L. (2014). DNA $\rightarrow$ RNA: What do students think the arrow means? CBE-Life Sciences Education, 13, 338-348. 